\title{
Three-dimensional numerical simulation of mechanical properties of soil-tire mixture by discrete element method
}

\author{
Mohsen Asadi ${ }^{1}$ and Ahmad Mahboubi ${ }^{1, *}$ \\ ${ }^{1}$ Shahid Beheshti University, Civil, Water and Environmental Eng. Dept., Tehran, Iran
}

\begin{abstract}
Soil engineering properties can be improved employing different methods. Among them is mixing soil with tire derived additives (TDA). TDAs generally increase some parameters of mixture such as damping ratio, permeability, ductility and also in some cases shear strength. Various properties of TDAs from mechanical properties to their geometry can affect the mixture behavior. In this paper using the YADE platform, simulations of triaxial tests on sand tire mixtures are presented. To take compressibility into consideration, each rubber crumb particle is made of several spheres connected elastically to each other. For sand particle generation the clump technique was employed. Shapes of both sand and rubber particles are inspired from real grains. As properties of sand and rubber are different, especially Young modulus, rubber sand interaction is considered as soft rigid contact. Therefor harmonic average and arithmetic average was used to compute contact Young modulus (and then stiffness). The model was validated by comparison of results of triaxial tests simulation on pure rubber sample with literature ones which both exhibited linear stress-strain curve. Then triaxial tests with different sand to rubber ratio were simulated to see whether harmonic average or arithmetic average gives the best match to literature. The results show shear strength reduces by decreasing of sand to rubber ratio. This is the same as what is reported in literature.
\end{abstract}

\section{Introduction}

As industrialization has begun, management of the consequences of this process has become an important issue for them. Governments have been eagerly embraced by industrial incentives, while neglecting the consequences of this, apart from undesirable social and cultural impacts, leads to costly phenomena. The growth of car production and, consequently, used tires are the result of the industrial development of the countries. Various methods have been proposed for reusing scrape tires. One of the ways that was introduced in civil projects about 3 decades ago was the mixing of soil with tire crumb.

Tire particles in civil projects are usually used in the form of crumbs and chips. Several cases have been mentioned for the use of tire particles alone - such as the backfill of the retaining walls - but concerns such as the occurrence of fire caused the tire particles to be mixed with sand. Figure 1 shows the recent firing in Sesena tire dumpsite in Spain.

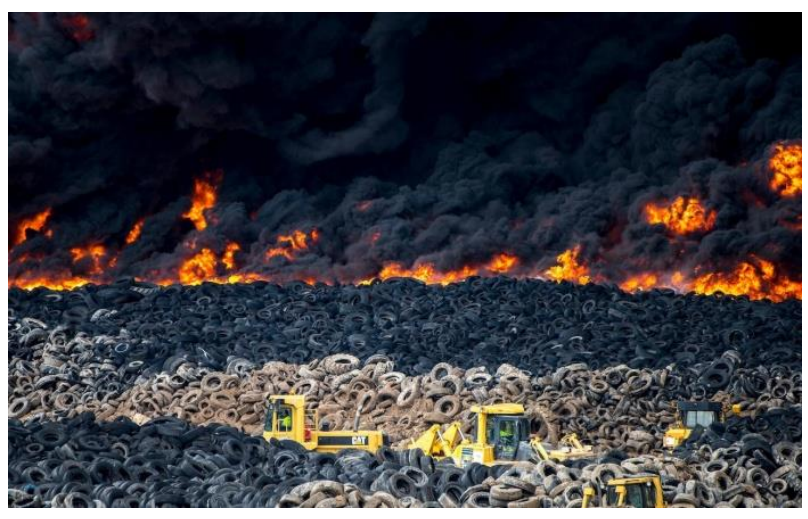

Figure 1. Fire in Sesena scrapes tire dumpsite

The percentage of tire derived additives, TDA, and their shapes to achieve the desired engineering properties are the subject of many studies in the field of geotechnics and are continuing so far. The main part of investigations includes laboratory studies, but numerical studies are pivotal.

The deformability and shape of TDA lead to a high interlocking where reports show that a backfill of TDA stands vertically even after removal of retaining wall [1].

\footnotetext{
* Corresponding author: a_mahboubi@sbu.ac.ir
} 
The Discrete Element Method, DEM, is a numerical method that uses a granular approach to simulate materials and subsequently can easily consider large deformations and heterogeneity of material. Therefore this method is now being used in powder technology, mine and pharmacology industries. DEM is a recent field of research in geotechnical engineering that, contrary to finite element method, considers soil as an assemblage of particles.

In this paper several triaxial tests on the sand-rubber mixture were simulated using the discrete element method. Based on research conducted by Asadi et al. [2], the deformability and shapes of grains is considered. For computing the contact stiffness between sand and rubber grains, two different approaches have been used. The results have been compared with literature.

\section{Discrete element modelling}

In this research YADE has been used for the simulations. YADE is a three-dimensional DEM code with several libraries to run geo-mechanical simulations. Although the $\mathrm{C}++$ language has been used for programming in YADE, the user should work with Python language as an easier method to write scripts. In the following the contact law, sample generation and loading of samples is described.

\subsection{Contact law}

In DEM the contact law determines how the forces on the in-contact particles are computed. The selection of contact law depends on the geometrical and mechanical properties of the modelling. Since considering the deformability of rubber grains is the objective of this research, the contact model should be capable of presenting the behaviour of contact in both tension and compression. Based on the terminology of this paper such contact is called cohesive contact where other ones are non-cohesive contact.

In this research a linear elastic contact law has been used.

Suppose that two particles with the positions of $\mathbf{C}_{1}$ $\left.x_{1}, y_{1}, z_{1}\right)$ and $\mathbf{C}_{2}\left(x_{2}, y_{2}, z_{2}\right)$, radius $r_{1}$ and $r_{2}$, and are in-contact at $\mathbf{C}_{c}\left(x_{c}, y_{c}, z_{c}\right)$. The Young's modulus of the two particles is $E_{1}$ and $E_{2}$. If the particles coordinates change for example to $\mathbf{C}_{\mathbf{1}}^{\prime}$ and $\mathbf{C}_{\mathbf{2}}^{\prime}$, then the normal force acting on the second sphere, $\mathbf{F}_{\mathbf{n}, 2}^{\mathrm{coh}}$, is calculated as:

$$
\mathbf{F}_{n}^{c o h}= \begin{cases}\left(k_{n} u_{n}\right) \mathbf{n} & \left|\mathbf{C}_{1}^{\prime}-\mathbf{C}_{2}^{\prime}\right|>\left|\mathbf{C}_{1}-\mathbf{C}_{2}\right| \quad \text { tension } \\ -\left(k_{n} u_{n}\right) \mathbf{n} & \left|\mathbf{C}_{1}^{\prime}-\mathbf{C}_{2}^{\prime}\right|<\left|\mathbf{C}_{1}-\mathbf{C}_{2}\right| \text { compression }\end{cases}
$$

where $k_{n}$ is the normal spring stiffness, $\mathrm{n}$ is the contact normal vector and $u_{n}$ is the normal displacement which activates the spring. They are defined as follows:

$$
k_{n}=\frac{E_{c} A_{c}}{\left|\mathbf{C}_{1}-\mathbf{C}_{2}\right|}
$$

$$
\begin{aligned}
& A_{c}=\pi\left(\min \left(r_{1}, r_{2}\right)\right)^{2} \\
& \mathbf{n}=\frac{\mathbf{C}_{1}^{\prime}-\mathbf{C}_{2}^{\prime}}{\left|\mathbf{C}_{1}^{\prime}-\mathbf{C}_{2}^{\prime}\right|} \\
& u_{n}=\| \mathbf{C}_{1}^{\prime}-\mathbf{C}_{2}^{\prime}|-| \mathbf{C}_{1}-\mathbf{C}_{2} \mid
\end{aligned}
$$

In previous studies (e.g. [3]) the modulus of contact was computed by taking and average of $E_{1}$ and $E_{2}$ :

$$
E_{c}=\frac{E_{1}+E_{2}}{2}
$$

This method is called arithmetic average. However another presented method is using harmonic average:

$$
E_{c}=\frac{2 E_{1} E_{2}}{\left(E_{1}+E_{2}\right)}
$$

If $E_{1}=E_{2}$, then equations (6) and (7) would lead to the same value; however in the case of different young modulus the computed values form equations (6) and (7) would not be the same. This paper uses both methods to see which one would lead to more realistic results when comparing with the literature.

If the contact is "non-cohesive", then only compressive normal forces can be generated, i.e.:

$$
\begin{array}{r}
\mathbf{F}_{n}^{\text {non }-c o h}=-\left(k_{n} u_{n}\right) \mathbf{n} \quad\left|\mathbf{C}_{1}^{\prime}-\mathbf{C}_{2}^{\prime}\right|<\left(r_{1}+r_{2}\right) \\
u_{n}=\left(r_{1}+r_{2}\right)-\left|\mathbf{C}_{1}^{\prime}-\mathbf{C}_{2}^{\prime}\right|
\end{array}
$$

The tangential or shear force for cohesive and noncohesive contacts is calculated as:

$$
\mathbf{F}_{t, 2}=\mathbf{F}_{t, 2}+k_{t} \Delta \mathbf{u}_{t}
$$

where $k_{t}$ is the shear stiffness and $\Delta \mathbf{u}_{t}$ is the incremental shear displacement. The maximum tangential force is defined as:

$$
F_{t}^{\max }=\tan \phi\left|F_{n}\right|
$$

where $\phi$ is the friction angle. Slip occurs if the tangential force is larger than $F_{t}^{\max }$.

The contact model parameters are derived from the research of Asadi et. al [2]. Table 1 show the model parameters that used for simulations: 
Table 1. Contact model parameters [2].

\begin{tabular}{|c|c|c|c|c|}
\hline Material & $\begin{array}{c}\text { Inter- } \\
\text { particle } \\
\text { friction } \\
\text { angle, } \\
\phi(\mathbf{d e g})\end{array}$ & $\begin{array}{c}\text { Contact } \\
\text { stiffness } \\
\text { ratio, } k_{n}\end{array}$ & $\begin{array}{c}\text { Young's } \\
\text { modulus, } \\
E(\mathbf{M P a})\end{array}$ & $\begin{array}{c}\text { Density } \\
\left(\mathbf{k g} / \mathbf{m}^{\mathbf{3}}\right)\end{array}$ \\
\hline Sand & 23 & 0.15 & 1000 & 2600 \\
\hline Rubber & 35 & 0.48 & 3.5 & 1500 \\
\hline Wall & 30 & 0.2 & 200,000 & - \\
\hline
\end{tabular}

\subsection{Sample generation}

The grain shapes here are the same as what is reported by Asadi et al [2]. Figure 2 shows the generated shapes. The sand grains are actually round-edges while the rubber grains are cubic.

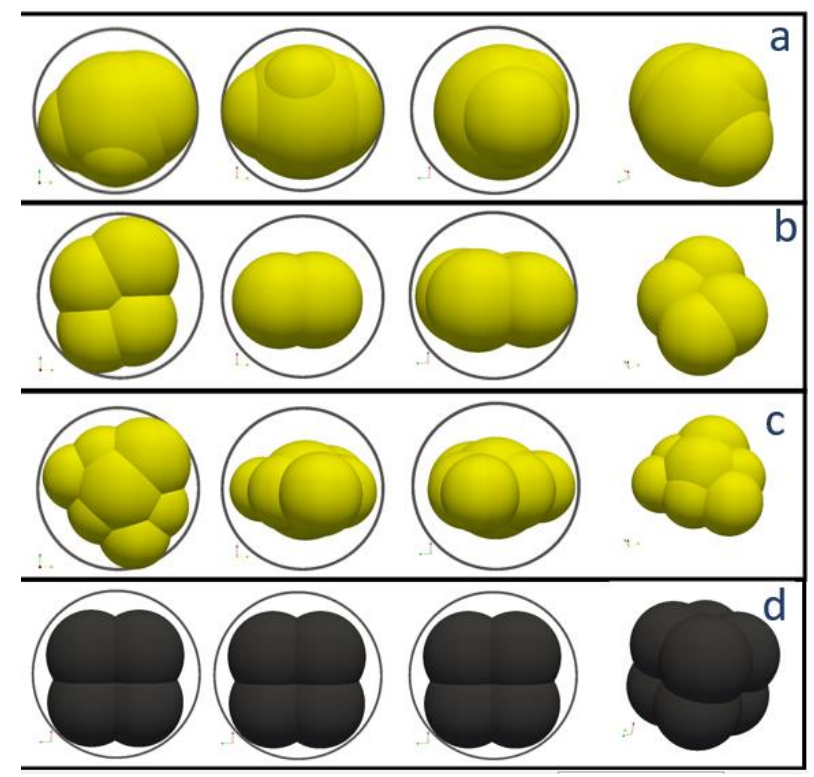

Figure 2. Grain shapes, (a-c) sand and (d) rubber

The size of all the grains is $4 \mathrm{~mm}$. A box with rigid walls has been used to apply loads. The confining pressure is 80 $\mathrm{kPa}$. After filling the box with the grains, the confining pressure is applied till the sample gets stable. Figure 3 shows some of generated samples.

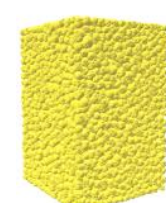

Pure sand sample

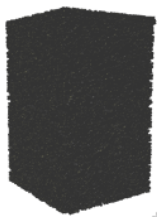

Pure rubber sample
Figure 3. Pure sand and pure rubber samples before shearing

\subsection{Loading}

After reaching a quasi-static situation, the shearing starts. The ratios of length to lateral dimension of samples are between 1.5 and 2 that is compatible with experimental triaxial tests. The rate of axial loading was $2 \%$.

\section{Results}

Figure 4 shows the triaxial response of pure rubber and pure sand samples and samples with $40 \%$ of rubber with two approaches of arithmetic and harmonic average to compute the contact Young modulus. The pure sand shows a peak stress point while the pure rubber curve increases linearly with strain. Such results are in agreement with experimental reported results (e.g. [4]). To grain a better knowledge of how the addition of rubber to samples change the response and then compare the arithmetic and harmonic average methods efficiency, an experimental results of triaxial tests is shown in Fig. 5.

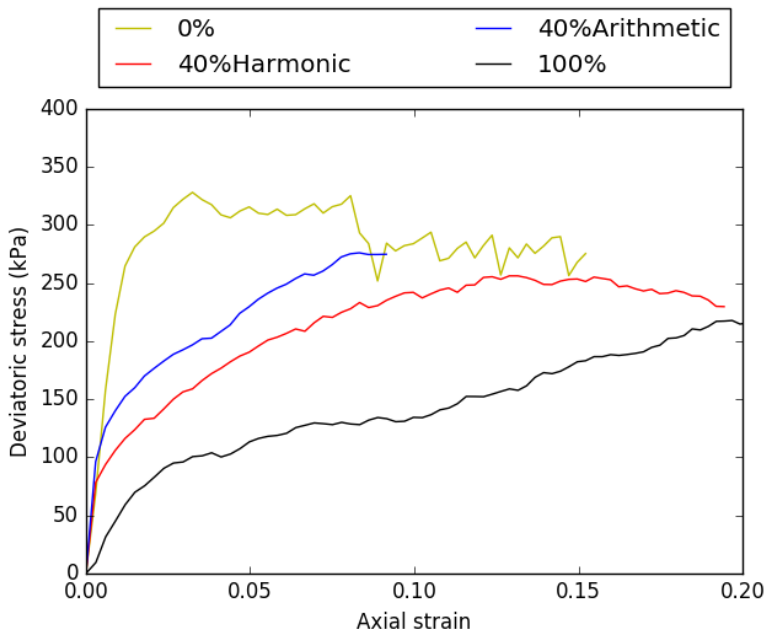

Figure 4. Triaxial test results for pure sand, pure rubber and $40 \%$ samples

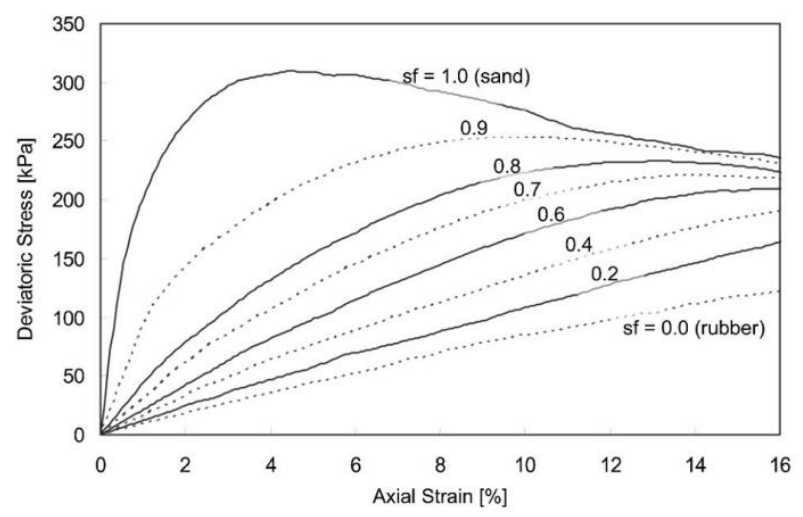

Figure 5. Triaxial test results reported by Lee et al. [5]. 'sf' means "sand fraction"

Based on figure 5 addition of rubber decrease the shear strength significantly. The samples with $\mathrm{sf}=0.6$, that is a sample with $40 \%$ rubber, shows a rather linear behaviour with no peak. Although in Fig. 4 both arithmetic and harmonic approaches shows a decrease in strength, however the arithmetic methods leads to higher values of stress rather than harmonic approach. It seems that harmonic approach produces more realistic results. Hence 
this approach was selected to investigate the effect of rubber addition on sand-rubber behaviour.

Figure 6(a) shows the deviatoric stress versus axial strain for different samples based on harmonic method. It is clear that samples with higher rubber ratio, exhibit lower strength which is in agreement with results of Fig. 5 and other reported results in the literature.

The variation of volumetric strain versus axial strain is shown Fig. 6(b). The pure sand sample shows dilative behaviour while the pure rubber sample shows a compressive behaviour. When the rubber content increases, the dilatancy behaviour decreases. The $40 \%$ sample shows compressive behaviour up to $15 \%$ strain and then the curves starts to rise showing dilatancy. In the samples with rubber content of less than $40 \%$, the dilatancy behaviour is clearer while for samples with rubber content more than $40 \%$ the compressive behaviour is more evident. Hence the $40 \%$ sample could be introduce as a boundary between sand-like behaviour and rubber-like behaviour that is in agreement with literature [6].
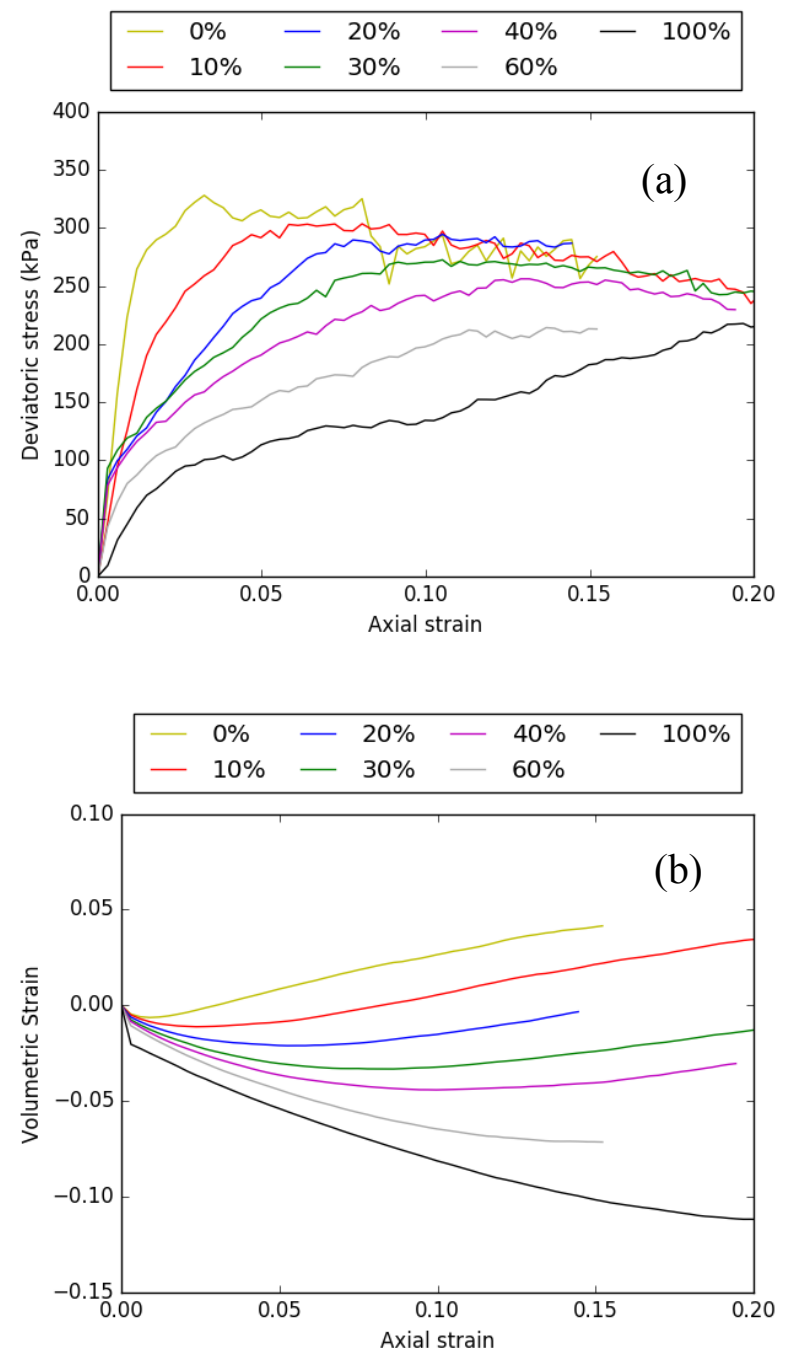

Figure 6. Triaxial test results using harmonic average method. (a) Deviatoric stress vs. axial strain and (b) volumetric strain vs. axial strain

\section{Conclusion}

Discrete element method is a suitable approach to model the binary mixtures. When the difference in stiffness of two mixed materials is very high, like sand and rubber, the harmonic average approach seems to produce more realistic results. Addition of rubber to sand decreases the shear strength and the dilatancy behaviour of sample.

\section{References}

1. J.H. Lee, R. Salgado, A. Bernal, C.W. Lovell: Shredded Tires and Rubber-Sand as Lightweight Backfill. Journal of Geotechnical and Geoenvironmental Engineering 125(2), 132-141 (1999).

2. M. Asadi, K. Thoeni, A. Mahboubi: An experimental and numerical study on the compressive behaviour of sand-rubber particle mixtures. Computers and Geotechnics 104, 185-195 (2018).

3. J.C. Lopera Perez, C.Y. Kwok, K. Senetakis: Effect of rubber size on the behaviour of sand-rubber mixtures: A numerical investigation. Computers and Geotechnics 80, 199-214 (2016).

4. S. Youwai, D.T. Bergado.: Strength and deformation characteristics of shredded rubber tire-sand mixtures. Canadian Geotechnical Journal 40(2), 254-264 (2003).

5. J. Lee, J. Dodds, J. Santamarina: Behavior of RigidSoft Particle Mixtures. Journal of Materials in Civil Engineering 19(2), 179-184 (2007).

6. T. Lok, H. Yu: Laboratory Study on the Mechanical Behaviour of Tire Chip-Sand Mixture. In: Pavement Mechanics and Performance. pp. 157-164. American Society of Civil Engineers, (2006) 